\title{
What we know about antibiotics prescribed by dentists in a Brazilian southeastern state
}

\begin{abstract}
Jacqueline Silva SANTOS(a) (iD
Alex Júnio Silva da CRUZ(a)

Cristina Mariano RUAS(b)

Edmilson Antônio PEREIRA JÚNIOR(c) (D)

Flávio de Freitas MATTOS(d) (D)

R. Monina KLEVENS(e)

Mauro Henrique Nogueira Guimarães ABREU(d) (iD)
\end{abstract}

(a) Universidade Federal de Minas Gerais - UFMG, School of Dentistry, Graduate Programme in Dentistry, Belo Horizonte, MG, Brazil.

(b) Universidade Federal de Minas Gerais UFMG, School of Pharmacy, Department of Social Pharmacy, Belo Horizonte, MG, Brazil.

(c) Universidade Federal de Minas Gerais UFMG, School of Education, Department of School Administration, Belo Horizonte, MG, Brazil.

(d) Universidade Federal de Minas Gerais UFMG, School of Dentistry, Department of Community and Preventive Dentistry, Belo Horizonte, MG, Brazil.

(e) Massachusetts Department of Public Health, Bureau of Infectious Disease and Laboratory Sciences, Boston, MA, USA.

Declaration of Interests: The authors certify that they have no commercial or associative interest that represents a conflict of interest in connection with the manuscript.

\section{Corresponding Author:}

Mauro Henrique Nogueira Guimarães Abreu E-mail: maurohenriqueabreu@gmail.com

https://doi.org/10.1590/1807-3107bor-2022.vol36.0002

Submitted: January 15, 2021

Accepted for publication: May 3, 2021

Last revision: May 21, 2021
Abstract: The objective of this study was to analyze possible associations between antibiotic dental prescriptions in the public health service, health service characteristics, and social characteristics of the municipalities. Using the register of dispensing in the public health service of a state in the Southeast region of Brazil, in 2017 we analyzed patterns of antibiotic prescriptions by dentists. Data were obtained from the Integrated Pharmaceutical Services Management System (SIGAF, in Portuguese). The outcome variable was the number of Daily Defined Doses (DDD) per 1,000 residents/year in each municipality. CART (Classification and Regression Tree) technique was used to determine the influence of the following variables: populational social characteristics (Human Development Index, Gini Index, the proportion of rural population and proportion of families benefiting from the Bolsa Família Program) and oral health services characteristics (access to individual dental care, number of dentists and oral health teams per 1,000 residents, and percentage of preventive and restorative individual dental procedures. Data analysis was performed using IBM SPSS Statistics 21.0. Antibiotics were the medications most prescribed by dentists in the public health service, with penicillin being the most frequently prescribed class. The average DDD/1,000 residents/year for the 421 municipalities surveyed was 96.54 (range 0.008 and 619.660). Select factors were associated with antibiotic prescriptions including access to individual dental care (Adjusted $p$-value $\leq 0.001$ ), a number of oral health teams $/ 1,000$ inhabitants (Adjusted p-value $=0.001$ ), and Gini Index (Adjusted p-value $=0.046$ ). Access to oral health services and inequality were associated with the use of antibiotics.

Keywords: Anti-Bacterial Agents; Dentistry; Drug Prescriptions.

\section{Introduction}

The World Health Organization prioritized the need for global action to fight antimicrobial resistance. ${ }^{1}$ Unreasonable antibiotic prescriptions have a broad impact on health systems because they cause adverse effects that can compromise patient safety, induce the development of resistant microorganisms, produce waste and increase costs, among others. $^{2}$ Antibiotic stewardship is the public health response that seeks to ensure that antibiotics are only prescribed and used when needed, 
and that when they are needed, the right drug, dose, and duration are selected. ${ }^{3}$ The One Health Approach, i.e. the collaborative effort of multiple health science professions to achieve health for human, animals, plants, and our environment, can explain how antimicrobial resistance can be related to the misuse of these drugs in animals, human and can results in impact in the environmental sector. ${ }^{4}$ There are different consumption rates and standard use of these drugs from one location to another, ${ }^{5}$ but the aspects associated with such differences have not been systematically studied. To minimize the consequences of antibiotic misuse since May 2011, the Brazilian government has determined that antibiotic dispensing requires a prescription by legally qualified health professionals; however, little scientific knowledge about their prescription and dispensing has been developed, especially in the public health sector.

Antibiotics, along with painkillers, are the medications most commonly prescribed by dentists for the treatment of dental and oral complaints. ${ }^{6,7}$ The prescription of antibiotics by dentists can be prophylactic or therapeutic and have increased over time. ${ }^{8,9,10}$ The standards of drug prescription in dental practices have been frequently researched by means of professionals' self-report ${ }^{11}$ without the objective evaluation of the actual prescriptions. There are few studies in literature that have already analyzed the standards of dental prescriptions in the private health sector, ${ }^{12,13}$ but in the public sector this subject has been little studied and is critical, given that $75 \%$ of the population is served by the public sector. ${ }^{14}$ Literature points to some factors that may explain the association between drug dispensing and socioeconomic characteristics of municipalities and service organization..$^{15}$ Moreover, aggregated data on antibiotic consumption may serve as a proxy for their actual use. ${ }^{5}$ Ecological studies have been more frequently developed in recent years because they present the potential to assess the occurrence of associations between context determinants and specific health outcomes in a population group. ${ }^{16}$ Thus, in current times it is extremely important that health services know the reality of antibiotic use and pay attention to controlling and preventing the spread of microbial resistance. In this way, they can contribute to increasing patient safety and to the effectiveness of antibiotic use, which can also result in reduced costs for health services. ${ }^{17}$

This work analyzed dental prescriptions of antibiotics, studying their dispensing in the Brazilian National Health System (BNHS, SUS in Portuguese) in the State of Minas Gerais in 2017 to determine the number of dentists in public health services, the proportion of the population with access to these services, and the socioeconomic conditions in the municipalities, and their association with rates of antibiotic prescriptions.

\section{Methodology}

This was an ecological study carried out in the State of Minas Gerais, located in the Southeastern region of Brazil. It is the second most populous state in the country $(21,168,791$ inhabitants), includes 853 municipalities with great social inequalities between them. In Brazil, Pharmaceutical Services are part of the BNHS and in Minas Gerais the State Secretary of Health (SES-MG) adopts the Integrated Pharmaceutical Services Management System (Sistema Integrado de Gerenciamento da Assistência Farmacêutica-SIGAF/SES-MG, in Portuguese) and collect information for the management of Pharmaceutical Services within BNHS.

Secondary data from SIGAF/SES-MG in 2017 were used, with prior authorization from the Superintendence of Pharmaceutical Assistance/ SES-MG. SIGAF/SES-MG databank was explored using Excel for Windows (Microsoft Inc., Redmond WA, USA) and SPSS version 21 (SPSS Inc., Chicago, USA). For all prescriptions registered in SIGAF in 2017, a cross match was conducted comparing the names of the prescribers in SIGAF and their respective registration numbers in the databank of the Regional Council of Dentistry of Minas Gerais (CRO-MG), which includes all dentists registered in the State. Dispensing performed after prescription by dentists identified in CRO-MG databank remained in the SIGAF databank. Other steps of exclusion of prescriptions and their criteria are described in Figure 1. 


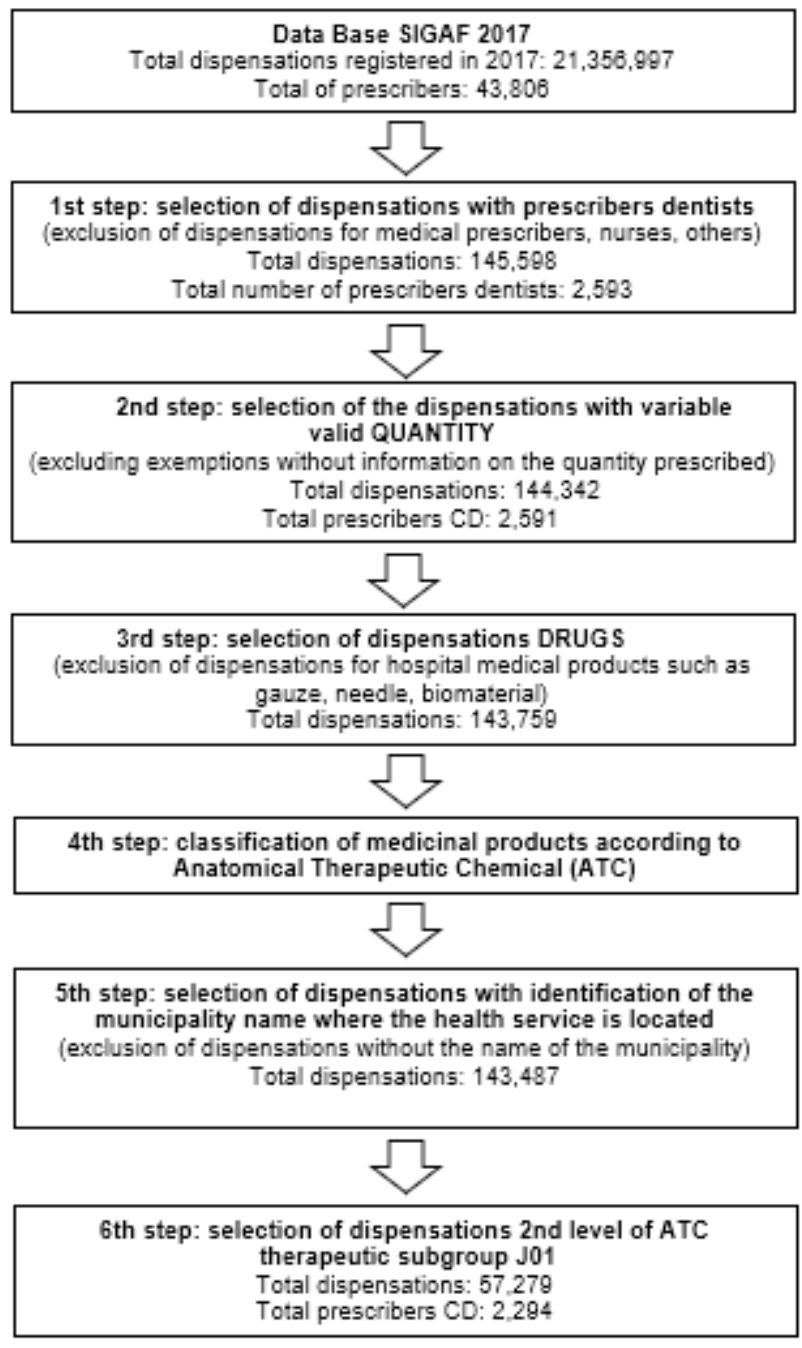

Figure 1. Flowchart of data extraction from SIGAF/SES-MG databank, 2017.

All drugs prescribed by dentists were classified according to the Anatomical Therapeutic Chemical Classification - ATC in the ATC/DDD Index 2019. ${ }^{18}$ The dispensing of drugs from the therapeutic subgroup J01 (antibiotics for systemic use) were selected. A Defined Daily Dose- DDD was assigned for each systemic antibiotic. ${ }^{18}$ Then, the individual DDD of each dispensing was calculated (number of units dispensed $x$ concentration of the drug) / DDD. ${ }^{18}$ From this individual databank, dispensing was grouped and the total DDD per municipality was calculated by summing up DDDs of all dispensed drugs. In this stage, the outcome variable (DDD/1,000 residents/year) of each municipality was calculated (number of municipal DDD x 1,000/ population), indicating the number of doses of a certain drug consumed for every 1,000 people in one year. ${ }^{18}$

Socioeconomic variables included in the study were Gini Index, Municipal Human Development Index, rate of families benefiting from Bolsa Família Program/1,000 residents and local proportion of rural residents. The following health service organization variables were included: the number of dentists working at $\mathrm{BNHS} / 1,000$ residents, access to individual dental care, number of oral health teams $/ 1,000$ residents, and percentage of preventive and restorative individual dental procedures. These covariates were taken from official Brazilian government databases and their description, all measured at municipal level, is presented in Table 1.

Descriptive statistical analysis and the CART (Classification and Regression Tree) technique were performed. The latter is a decision tree based on a response variable and a set of explanatory variables. ${ }^{19}$ The tree analyzed in this study was of the regression type, since it had a numerical response variable, and the analytical model created was composed of a dependent variable and eight independent variables. The logic of the CART technique lies in the fact that trees are constructed by subdividing groups into subgroups in ongoing manner. The implementation of successive divisions of the total data set uses the CHAID method (Chi-square Automatic Interaction Detection). In each division the technique chooses the independent variable that has the strongest interaction with the dependent variable. In addition, it groups the categories of each variable that are not significantly different from the dependent variable. In the development of CART some criteria are established: first, each node - denomination given to each subset resulting from the application of a division rule - should have a minimum of 50 observations to perform the subdivisions; second, each end node should have a minimum of 30 observations; third, the model disregards subdivisions with probability of significance $p \geq 0,05 .{ }^{19}$ All statistical analysis was performed using SPSS software version 25 (SPSS Inc., Chicago, USA). 
Table 1. Description of the independent variables at municipal level.

\begin{tabular}{|c|c|c|c|}
\hline Variables & Description & Reference year & Source \\
\hline \multicolumn{4}{|l|}{ Socioeconomic } \\
\hline Gini Index & $\begin{array}{l}\text { Measure of the degree of concentration of income in a society, } \\
\text { Range: } 0 \text { to } 1.1 \text { corresponds to maximal inequality. }\end{array}$ & 2010 & DATASUS \\
\hline $\begin{array}{l}\text { Municipal Human Development } \\
\text { Index-IDHM }\end{array}$ & $\begin{array}{c}\text { Measure composed of three indicators: longevity, education } \\
\text { and income. Range: } 0 \text { to } 1 \text {. The closer to } 1 \text { the greater human } \\
\text { development. }\end{array}$ & 2010 & $\begin{array}{l}\text { Atlas of Human } \\
\text { Development in } \\
\text { Brazil }\end{array}$ \\
\hline \multirow[t]{2}{*}{$\begin{array}{l}\text { Rate of benefited families with } \\
\text { Bolsa Família Program per } \\
1,000 \text { residents }\end{array}$} & $\begin{array}{c}\text { Bolsa Familia Program is a program that contributes to the fight } \\
\text { against poverty and inequality in Brazil. Its axes are the complement } \\
\text { of family income and access to social rights such as education and } \\
\text { health. }\end{array}$ & \multirow[t]{2}{*}{2017} & \multirow[t]{2}{*}{$\begin{array}{l}\text { Ministry of } \\
\text { Citizenship }\end{array}$} \\
\hline & $\begin{array}{l}\text { Formula: (number of families benefited by the Bolsa Família Program } \\
\qquad \times 1,000 \text { residents) / total population. }\end{array}$ & & \\
\hline Proportion of rural population & $\begin{array}{l}\text { Proportion of rural resident population } \\
\text { Formula: (rural population / total population) x } 100 \text {. }\end{array}$ & 2010 & IBGE \\
\hline \multicolumn{4}{|l|}{ Oral Health Service Characteristics } \\
\hline $\begin{array}{l}\text { Number of Dentists in } \\
\text { the Brazilian National } \\
\text { Health System (SUS) per } \\
1,000 \text { residents }\end{array}$ & $\begin{array}{l}\text { The rate of dentists working in the SUS per 1,000 residents. } \\
\text { Formula: (number of dentists in the SUS/ total population) x } \\
\qquad 1,000 \text { residents. }\end{array}$ & December & DATASUS \\
\hline Access to individual dental care & $\begin{array}{l}\text { Proportion of residents who receive a scheduled primary dental } \\
\text { consultation with the aim of diagnosing and elaborating a } \\
\text { preventive/therapeutic plan to address the detected needs. } \\
\text { Formula: (number of residents who receive the first dental } \\
\text { appointments / total population) x } 100 \text {. }\end{array}$ & 2017 & DATASUS \\
\hline $\begin{array}{l}\text { Number of oral health } \\
\text { teams/1,000 residents }\end{array}$ & $\begin{array}{l}\text { Proportion of dentist, oral health assistant and/ or oral health } \\
\text { technician at BNHS among the population. } \\
\text { Formula: number of oral health teams / (total population) x } \\
\qquad 1,000 \text { residents }\end{array}$ & December & DATASUS \\
\hline $\begin{array}{l}\text { Percentage of individual } \\
\text { preventive and restorative } \\
\text { dental procedures }\end{array}$ & $\begin{array}{c}\text { Formula: (number individual preventive and restorative dental } \\
\text { procedures x 100) / total number individual preventive, restorative } \\
\text { and surgical dental procedures }\end{array}$ & 2017 & DATASUS \\
\hline
\end{tabular}

DATASUS: Information Technology Department of the BNHS; IBGE: Instituto Brasileiro de Geografia e Estatística; inhab: inhabitants.

The study was approved by the Research Ethics Committee of the Federal University of Minas Gerais under number CAAE- 88465118.8.0000.5149.

\section{Results}

Socioeconomic and oral health service characteristics of the 421 municipalities in Minas Gerais that dispensed systemic antibiotics prescribed by dentists in 2017 are shown in Table 2 .

Systemic antibiotics were the most prescribed group of medications of all dental prescriptions $(n=$
57,279/143,487; 39.92\%). Among antibiotics, the most dispensed medications were amoxicillin (88.46\%), azithromycin (8.89\%), amoxicillin with clavulanic acid (3.04\%), and cephalexin (2.24\%) (Table 3). The mean DDD/1,000 residents/year for the 421 municipalities was 96.54 ( $\mathrm{SD}=111.35$ ), with minimum and maximum values of 0.008 and 619.660, respectively, and median equal to 53.25 .

Figure 2 presents the results of CART statistical analysis. Evaluating the influence of the eight independent variables on the Root Node (N0), the one that showed the greatest potential for differentiation 
Table 2. Socioeconomic and oral health service characteristics of the 421 municipalities that have dispensed systemic antibiotics prescribed by dentists, SIGAF, 2017.

\begin{tabular}{lcc}
\hline Covariates & Mean & Median \\
\hline Gini Index 2010 & 0.48 & 0.48 \\
HDI 2010* & 0.66 & 0.67 \\
Rate of benefited families with Bolsa Família Program per 1,000 residents & 77.91 & 70.05 \\
Proportion of rural population & 32.37 & 30.01 \\
Number of Dentists in the Brazilian National Health System (SUS) per 1,000 residents & 0.60 & 0.51 \\
Access to individual dental care & 19.97 & 7.67 \\
Number of oral health teams/1,000 residents & 0.28 & 0.29 \\
Percentage of individual preventive and restorative dental procedures & 90.49 & 91.53 \\
\hline
\end{tabular}

*HDI: Human Development Index.

Table 3. Antibiotics prescribed by dentists and dispensed in the public health service, Minas Gerais, 2017

\begin{tabular}{|c|c|c|c|c|}
\hline ATC code & ATC* name & $\mathrm{N}^{\circ}$ dispensings & $\mathrm{N}^{\circ}$ units dispensed & $N^{\circ}$ DDD \\
\hline J01AA02 & Doxycycline & 11 & 135 & 135.00 \\
\hline J01CA01 & Ampicilin & 14 & 346 & 86.50 \\
\hline J01CA04 & Amoxicillin & 48381 & 934601 & 327862.83 \\
\hline J01CE08 & Benzylpenicillin Benzatin & 43 & 91 & 18.20 \\
\hline J01CE09 & Benzylpenicillin Procaine & 1 & 1 & 0.30 \\
\hline J01CR02 & Amoxicillin + Potassium Clavulanate & 1739 & 34100 & 12770.83 \\
\hline J01DB01 & Cefalexin & 1285 & 29700 & 8304.75 \\
\hline J01EC02 & Sulfadiazine & 3 & 50 & 41.66 \\
\hline J01EE01 & Sulfametoxazole + Trimethroprim & 229 & 4486 & 273.10 \\
\hline J01FA01 & Erythromycin & 32 & 449 & 274.50 \\
\hline J01FA09 & Clarithromycin & 8 & 152 & 152.00 \\
\hline J01FA10 & Azithromycin & 5091 & 21037.5 & 35216.5 \\
\hline J01FF01 & Clindamycin & 10 & 228 & 57.00 \\
\hline J01MA02 & Ciprofloxacin & 377 & 6661 & 3330.50 \\
\hline J01MA06 & Norfloxacin & 19 & 329,5 & 164.75 \\
\hline J01MA12 & Levofloxacin & 13 & 133 & 133 \\
\hline J01XE01 & Nitrofurantoin & 23 & 855 & 427.50 \\
\hline Total & & 57279 & 1033355 & 389248.92 \\
\hline
\end{tabular}

*ATC: Anatomical Therapeutic Chemical Classification.

was "access to individual dental care", therefore the proportion of the population that have received a scheduled primary dental appointment have influenced the outcome. The influence of this variable divided the municipalities into two groups: $\mathrm{N} 1$ for municipalities with access to individual dental care $\leq 9.211(\mathrm{n}=253$; mean DDD = 78.816) and N2 for municipalities with access to individual dental care $>9.211(\mathrm{n}=168$; mean $\mathrm{DDD}=123.22)$. This value was defined by software syntax which makes adjustments to verify where this greater differentiation occurred. Successive divisions of the subgroup compared and identified how other variables interfered in subgroups N1 and N2. Among group N2 no variable had significant differentiation potential, i.e., no other variable distinguished the model with significance. 
On the other hand, in group N1 variable "number of oral health teams/1,000 residents" presented greater differentiation and divided this group of municipalities into two further groups: N3 presented number of oral health teams $/ 1,000$ residents $\leq 0.253$ $(\mathrm{n}=119 ;$ mean $\mathrm{DDD}=54.057)$ and N4 with number of oral health teams $/ 1,000$ residents $>0.253$ ( $n=134$; mean DDD $=100.804)$. Therefore, the density of dental professionals was associated with antibiotic prescribing. Further divisions were carried out to identify which variable interfered in groups N3 and N4. In N4 group of municipalities no variable presented differentiation potential. However, in group N3 variable "Gini Index" induced differentiation and subdivided this group into two new groups of municipalities: N5 with Gini Index $\leq 0.522$ ( $\mathrm{n}=87$; mean DDD $=62.256$ ) and N6 with Gini Index $>0.522$ $(\mathrm{n}=32$; mean DDD $=23.612)$. This indicates that municipalities with lower income inequalities had higher average DDD/1,000 residents/year. The smallest response variable was in N6 (mean DDD $=23.612$ ) and the largest was in N2 (mean DDD = 123.22). The independent variable that presented the highest association with the outcome variable was "access to individual dental care", when population coverage was $>9.211 \%$, while the one that presented the lowest association was "Gini Index" $>0.522$.

\section{Discussion}

Antibiotics were the drugs most prescribed by dentists in the public health service in Minas Gerais and penicillin was the most frequently prescribed class. Socioeconomic and health services organizational factors were associated with the use of these drugs. This is the first population-based study on the quantity and pattern of antibiotics prescribed by dentists in the public health sector in Brazil.

The highest prescription rate of antibiotics, among all dental prescriptions, is consistent with findings

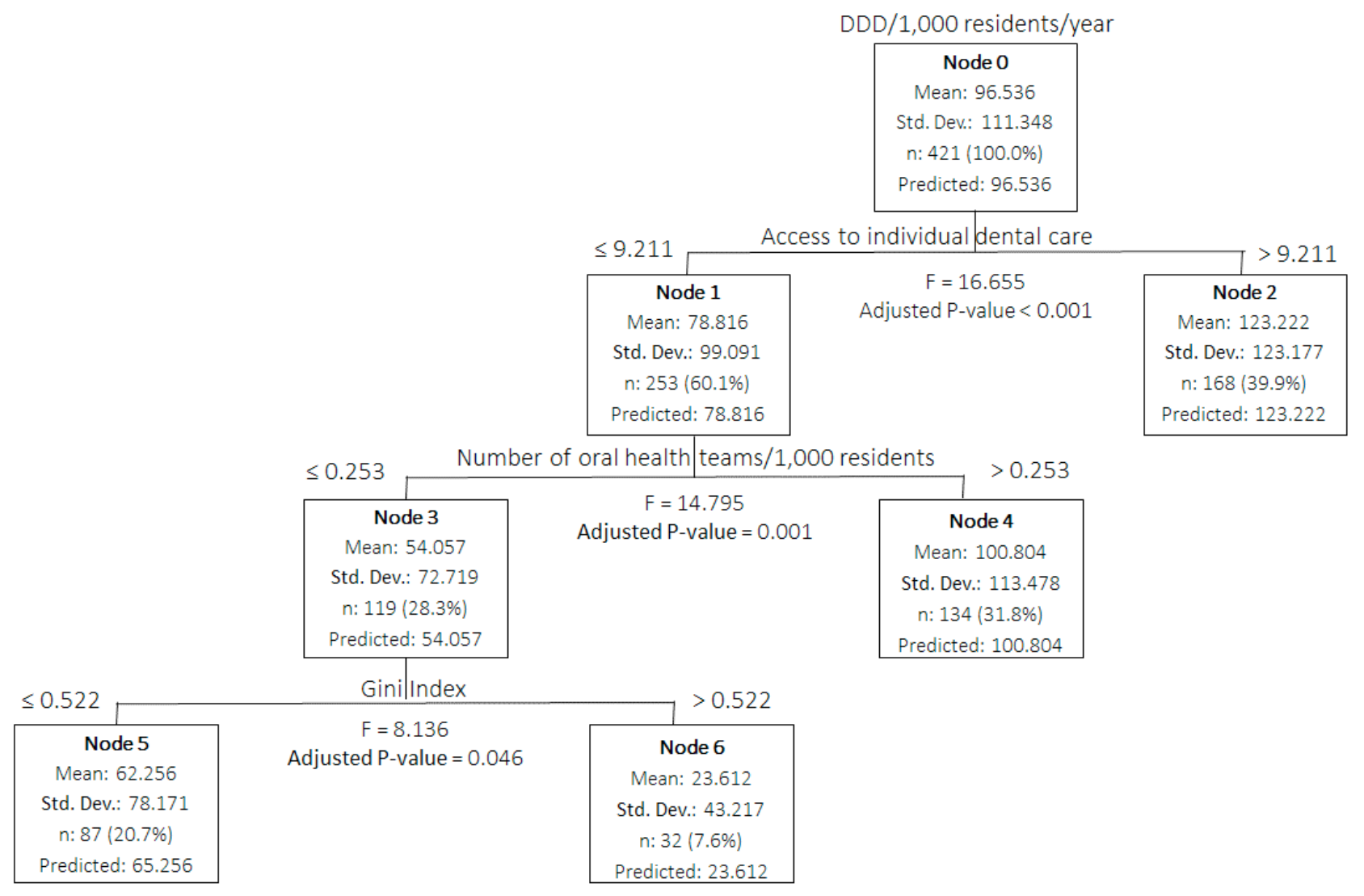

Figure 2. Regression tree of DDD/1,000 residents/year according to independent variables. 
of other studies. ${ }^{6-8}$ It is not an easy task to compare $\mathrm{DDD} / 1,000$ residents/year in our study and others. Firstly, because few studies evaluate DDD indicators to analyze dental prescriptions. ${ }^{8,9,10,20}$ Among these manuscripts DDD was not measured for each municipality. When we compared the mean DDD for all 412 municipalities, we found lower values than in British Columbia, Canada, Australia and Belgium. 8,910,20 Differences in the access to dental services among those countries and, also, overprescribing of antibiotics could explain these differences. The demand for dental care related to dentoalveolar infection and the belief that antibiotic therapy is the most effective measure in the management of such cases may be one of the reasons why dentists prescribe and patients demand antibiotics in those clinical situations. ${ }^{11,20}$ Studies indicate that antibiotics are often inappropriately prescribed by dentists. ${ }^{9,11,20,21,22}$ It is worth noting that there is no current evidence that antibiotics are effective in managing inflammatory conditions such as acute apical periodontitis, alveolar osteitis and irreversible pulpitis. ${ }^{22,23,24}$ Only in select situations when same day definitive treatment cannot be provided, an American Dental Association panel recommended antibiotics be considered for management of urgent pulpal and periapical pain and swelling. ${ }^{25}$ There is a clear relationship between humans, animals, plants and the environment, which is discussed by the One Health approach. The misuse of antimicrobials in any group could affect the others, with public health consequences at local, national and international levels. ${ }^{4}$

Of all antibiotics, it is appropriate that the highest frequency of prescriptions was amoxicillin. A first aspect may be related to the uncertainty of dentists in the presence of an odontogenic or orofacial infection, involving microorganisms. ${ }^{21}$ In such cases dentists may be unable to perform same day definitive treatment and choose to empirically prescribe a bactericidal antibiotic of broad spectrum. They are effective against a variety of gram positive and negative bacteria. This clinical conduct may also be present in cases where dentists make the clinical decision to prescribe antibiotics such as amoxicillin to prevent postoperative infectious complications. ${ }^{20,26}$ However, there are studies that point to a lack of justification for prescribing broad spectrum antibiotics. They instruct policy makers to apply restrictive measures aimed at improving antibiotic prescription standards. ${ }^{20}$ The posological convenience of amoxicillin may also have contributed to its increased frequency of prescription and dispensing. ${ }^{23}$ The finding that amoxicillin with clavulanic acid did not have a dispensing frequency higher than amoxicillin can be considered positive, since to avoid the development of more resistance, antibiotics should always be prescribed at the lowest possible spectrum. ${ }^{20}$ Another possible explanation for the lower prescription of this formulation may be related to its smaller availability in the stocks of public service pharmacies in Brazil, when compared to amoxicillin. Although there are limited indications for prophylactic antibiotic therapy for dental procedures aimed at preventing bacterial endocarditis (e.g., patient history of bacterial endocarditis), dentists usually prescribe antibiotics for this purpose and amoxicillin is the most frequently selected. ${ }^{27}$ In recent decades, an increasing number of bacterial species have become resistant to amoxicillin, which exacerbates the problem of microbial resistance to antibiotics, making it one of the most critical health problems in the world. It is currently suggested that dentists should avoid administering amoxicillin to healthy patients, especially for third molar exodontics. ${ }^{28}$

The process of prescribing, distributing and using medicines is related to their availability in health services. ${ }^{29}$ The presence of professionals in health services is essential to medicine prescription. In this sense, higher rates of oral health teams/1,000 residents/year have contributed for higher averages of DDD/1,000 residents/year. Furthermore, the epidemiological profile of the Brazilian population is of high prevalence and severity of oral diseases and dentists frequently perform emergency care. ${ }^{30,31}$ Access to individual dental care is a proxy of individual access to any type dental treatment at primary health care in the BNHS, i.e. the higher this value, the higher proportion of the population of each municipality with access to individual dental treatment. ${ }^{32}$ The association between access to individual dental care and the use of antibiotics may indicate that, in general, antibiotics were associated with clinical interventions, as recommended in the literature. ${ }^{26}$ Moreover, even considering that from a legal point of view BNHS is 
an universal and free system, it still delivers limited population coverage. ${ }^{33,34}$ Limited access to specialized dental services may lead to more teeth extraction caused by the lack of access to essential preventive and restorative treatments at primary health care level. ${ }^{35}$ The positive association between greater access to individual dental care and DDD/1,000 residents/ year warrants further study to evaluate whether municipalities presented fewer dental emergencies and could instead provide comprehensive dental care. This result is important for health managers to evaluate the type of care being offered to the population, since antibiotic therapy should complement dental treatment and access to specialized services in the BNHS is restricted. We hypothesized that the type of dental treatment offered at primary health care, measured by the percentage of individual preventive and restorative dental procedures, could influence dental prescriptions rates. Municipalities with lower percentages of preventive and restorative procedures, i.e. with higher rates of surgical procedures, could have higher rates of DDD/1,000 residents/year. However, this covariate did not influence our outcome. It seems that having access to dental treatment is more important to define dental prescription of antibiotics rather than the type of dental procedure. Other researches at PHC could be developed to identify the relationship between these variables at an individual level.

Municipalities with lower Gini index, i.e. with lower inequalities in income distribution, presented higher average DDD/1,000 residents/year. A similar result associating Gini index and opioid analgesics prescription was found in a recent study in the United States. ${ }^{36}$ It is reasonable to assume that less inequality in income distribution can favor access to oral health services, which is in line with the knowledge of social determinants of health. ${ }^{37}$ This finding should be analyzed with attention, because antibiotics could be required in cases of dental-alveolar infection and the greater the inequality in income distribution, the lower is the chance of a person reporting good oral health status in Brazil. ${ }^{38}$ Furthermore, greater equality in income distribution by itself does not describe if the mean income is high or low. Therefore, it cannot be assumed that good income distribution translates into social justice, but might reflect better access to care, albeit potentially overprescribed antibiotics. ${ }^{39,40}$ It is important to notice that empirical studies have been carried out seeking to link income inequality to health problems, but recent systematic reviews have failed to reach a consensus due to contradictory results. ${ }^{41}$ On the other hand, it is also important to point out that other socioeconomic variables did not influence dental prescriptions.

This study has inherent limitations common to all studies using secondary data, such as the impossibility of controlling and/or ensuring all data quality. It should also be noted that cross-sectional analysis makes it possible to identify associations but it does not allow to establish a causal relationship between covariates and the studied outcome. Further analyses could be performed to determine whether independent variables associated with the outcome at municipal level remain significant at the individual level. Advances in the surveillance system of antibiotic prescriptions in the public service could include other data based on the International Code of Diseases (ICD), in order to evaluate therapeutic rationality. However, this study advances in the population approach to the evaluation of antibiotic dental prescriptions in the public health service from a large Brazilian state, and for the first time identifies non-clinical factors associated with prescribing.

\section{Conclusion}

The dispensing of antibiotics prescribed by dentists was associated with non-clinical variables, such as socioeconomic factors and the organization of public health services.

\section{Acknowledgments}

We thank the Superintendência de Assistência Farmacêutica - Secretaria de Estado de Saúde de Minas Gerais (SES-MG), for providing access to databank. This study was partially financed by the National Council for Scientific and Technological Development (CNPq), the Coordenação de Aperfeiçoamento de Pessoal de Nível Superior (CAPES), the Minas Gerais State Research Support Foundation (FAPEMIG) and the Pró-reitoria de Pesquisa da Universidade Federal de Minas Gerais (PRPq/UFMG). 


\section{References}

1. World Health Organization. Global action plan on antimicrobial resistance. Geneva: World Health Organization; 2015 [cited 2020 Nov 19]. Available from: https://www.who.int/antimicrobial-resistance/publications/global-action-plan/en/

2. World Health Organization. The world medicines situation 2011. Rational use of medicin. Geneva: World Health Organization; 2011. [cited 2020 Nov 19]. Available from: https://www.who.int/medicines/areas/policy/world_medicines_situation/WMS_ch14_wRational.pdf

3. Sanchez GV, Fleming-Dutra KE, Roberts RM, Hicks LA. Core elements of outpatient antibiotic stewardship. MMWR Recomm Rep. 2016 Nov;65(6):1-12. https://doi.org/10.15585/mmwr.rr6506al

4. McEwen SA, Collignon PJ. Antimicrobial resistance: a one health perspective. Microbiol Spectr. 2018 Mar;6(2):1-26. https://doi.org/10.1128/microbiolspec.ARBA-0009-2017

5. World Health Organization. WHO report on surveillance of antibiotic consumption: 2016-2018 early implementation. Geneva: World Health Organization; 2018 [cited 2020 Nov 19]. Available from: https://apps.who.int/iris/bitstream/hand le/10665/277359/9789241514880-eng.pdf?ua=1

6. Jayadev M, Karunakar P, Vishwanath B, Chinmayi SS, Siddhartha P, Chaitanya B. Knowledge and pattern of antibiotic and non narcotic analgesic prescription for pulpal and periapical pathologiesv: a Survey among dentists. J Clin Diagn Res. 2014 Jul;8(7):ZC10-4. https://doi.org/10.7860/JCDR/2014/9645.4536

7. Bunce JT, Hellyer P. Antibiotic resistance and antibiotic prescribing by dentists in England 2007-2016. Br Dent J 2018;13;225(1):81-4. https://doi.org/10.1038/sj.bdj.2018.525

8. Marra F, George D, Chong M, Sutherland S, Patrick DM. Antibiotic prescribing by dentists has increased: why? J Am Dent Assoc. 2016 May;147(5):320-7. https://doi.org/10.1016/i.adaj.2015.12.014

9. Ford PJ, Saladine C, Zhang K, Hollingworth SA. Prescribing patterns of dental practitioners in Australia from 2001 to 2012. Antimicrobials. Aust Dent J. 2017 Mar;62(1):52-7. https://doi.org/10.1111/adj.12427

10. Struyf T, Vandael E, Leroy R, Mertens K, Catry B. Antimicrobial prescribing by Belgian dentists in ambulatory care, from 2010 to 2016. Int Dent J. 2019 Dec;69(6):480-7. https://doi.org/10.1111/idj.12512

11. Sturrock A, Landes D, Robson T, Bird L, Ojelabi A, Ling J. An audit of antimicrobial prescribing by dental practitioners in the north east of England and Cumbria. BMC Oral Health. 2018 Dec;18(1):206. https://doi.org/10.1186/s12903-018-0682-4

12. Lisboa SM, Souza GL, Silva ME, Abreu MH. Legal Aspects of dental antibiotic prescriptions: a descriptive study in a large brazilian city. Pesqui Bras Odontopediatria Clin Integr. 2014;14(3):207-17. https://doi.org/10.4034/PBOCI.2014.143.05

13. Lino PA, Sohn W, Singhal A, Martins MA, Silva ME, Abreu MH. A national study on the use of opioid analgesics in dentistry. Braz Oral Res. 2019 Aug;33:e076. https://doi.org/10.1590/1807-3107bor-2019.vol33.0076

14. World Health Organization. Brazil's march towards universal coverage. Bull World Health Organization. 2010 [cited 2020 Oct 9];88(9):641-716. Available from: https://www.who.int/bulletin/volumes/88/9/10-020910/en/\#: :text=Two\%20decades\%20after\%20 establishing\%20its,for\%20their\%20health\%20care\%20coverage

15. Barros RD, Costa EA, Santos DB, Souza GS, Álvares J, Guerra AA, et al. Access to medicines: relations with the institutionalization of pharmaceutical services. Rev Saúde Pública. 2017 Nov;51(2 suppl 2):8s. https://doi.org/10.11606/S1518-8787.2017051007138

16. Loney T, Nagelkerke NJ. The individualistic fallacy, ecological studies and instrumental variables: a causal interpretation. Emerg Themes Epidemiol. 2014 Nov;11(1):18. https://doi.org/10.1186/1742-7622-11-18

17. Cope AL, Chestnutt IG. Inappropriate prescribing of antibiotics in primary dental care: reasons and resolutions. Prim Dent J. 2014 Nov;3(4):33-7. https://doi.org/10.1308/205016814813877333

18. World Health Organization. Collaborating Centre for Drug Statistics Methodology. ATC classification and DDD assignment. Oslo: World Health Organization; 2019 [cited 2020 Sep 16]. Available from: https://www.whocc.no/atc_ddd_index/

19. Breiman L, Friedman J, Stone CJ, Olshen RA. Classification and regression trees. United Kingdom: CRC Press; 1998.

20. Teoh L, Stewart K, Marino RJ, McCullough MJ. Part 1. Current prescribing trends of antibiotics by dentists in Australia from 2013 to 2016. Aust Dent J. 2018 May;63(3):329-37. https://doi.org/10.1111/adj.12622

21. Oberoi SS, Dhingra C, Sharma G, Sardana D. Antibiotics in dental practice: how justified are we. Int Dent J. 2015 Feb;65(1):4-10. https://doi.org/10.1111/idj.12146

22. Cope AL, Barnes E, Howells EP, Rockey AM, Karki AJ, Wilson MJ, et al. Antimicrobial prescribing by dentists in Wales, UK: findings of the first cycle of a clinical audit. Br Dent J. 2016 Jul;221(1):25-30. https://doi.org/10.1038/sj.bdj.2016.496

23. Germack M, Sedgley CM, Sabbah W, Whitten B. Antibiotic use in 2016 by members of the American Association of Endodontists: report of a national survey. J Endod. 2017 Oct;43(10):1615-22. https://doi.org/10.1016/i.joen.2017.05.009

24. Thompson W, Rios LE, Fedorowicz Z, Dailey Y, Douglas G. I've got toothache, I need antibiotics: a UK perspective on rational antibiotic prescribing by dentists. Braz Dent J. 2018 Jul-Aug;29(4):395-9. https://doi.org/10.1590/0103-6440201802200 
What we know about antibiotics prescribed by dentists in a Brazilian southeastern state

25. Lockhart PB, Tampi MP, Abt E, Aminoshariae A, Durkin MJ, Fouad AF, et al. Evidence-based clinical practice guideline on antibiotic use for the urgent management of pulpal-and periapical-related dental pain and intraoral swelling: A report from the American Dental Association. J Am Dent Assoc. 2019 Nov;150(11):906-921.e12. https://doi.org/10.1016/i.adaj.2019.08.020

26. American Association of Endodontics. AAE position statement: AAE guidance on the use of systemic antibiotics in endodontics. J Endod. 2017 Sep;43(9):1409-13. https://doi.org/10.1016/i.joen.2017.08.015

27. Lisboa SM, Martins MA, Castilho LS, Souza e Silva ME, Abreu MH. Prescribing errors in antibiotic prophylaxis by dentists in a large Brazilian city. Am J Infect Control. 2015 Jul;43(7):767-8. https://doi.org/10.1016/i.ajic.2015.03.028

28. Menon RK, Gopinath D, Li KY, Leung YY, Botelho MG. Does the use of amoxicillin/amoxicillin-clavulanic acid in third molar surgery reduce the risk of postoperative infection? A systematic review with meta-analysis. Int J Oral Maxillofac Surg. 2019 Feb;48(2):263-73. https://doi.org/10.1016/j.ijom.2018.08.002

29. Santos JS, Cruz AJ, Castilho LS, Abreu MH. Availability of analgesic and anti-inflammatory medicines in primary health care. Braz Res Ped Dent Integrat Clinic 2020;20:e5236. https://doi.org/10.1590/pboci.2020.045

30. Noro LR, Roncalli AG, Mendes Júnior FI, De Lima KC, Teixeira AK. Toothache and social and economic conditions among adolescents in Northeastern Brazil. Cienc Saude Colet 2014;19(1):105-13. https://doi.org/10.1590/1413-81232014191.2110

31. Silva Junior MF, Sousa MD, Batista MJ. Reducing social inequalities in the oral health of an adult population. Braz Oral Res. 2020 Jan;33:e102. https://doi.org/10.1590/1807-3107bor-2019.vol33.0102

32. Esteves RS, Mambrini JV, Oliveira AC, Abreu MH. Performance of primary dental care services: an ecological study in a large Brazilian city. ScientificWorldJournal. 2013 Dec;2013:176589. https://doi.org/10.1155/2013/176589

33. Aranha RL, Pinto RS, Abreu MH, Martins RC. Factors associated with toothache among Brazilian adults: a multilevel analysis. Braz Oral Res. 2020 Apr;34:e036. https://doi.org/10.1590/1807-3107bor-2020.vol34.0036

34. Massoni AC, Porto É, Ferreira LR, Silva HP, Gomes MD, Perazzo MF, et al. Access to oral healthcare services of adolescents of a largesize municipality in northeastern Brazil. Braz Oral Res. 2020 Mar;34:e029. https://doi.org/10.1590/1807-3107bor-2020.vol34.0029

35. Cunha MA, Lino PA, Santos TR, Vasconcelos M, Lucas SD, Abreu MH. 15-Year time-series study of tooth extraction in Brazil. Medicine (Baltimore). 2015 Nov;94(47):e1924. https://doi.org/10.1097/MD.0000000000001924

36. Zhou C, Yu NN, Losby JL. The association between local economic conditions and opioid prescriptions among disabled Medicare beneficiaries. Med Care. 2018 Jan;56(1):62-8. https://doi.org/10.1097/MLR.0000000000000841

37. da Silva JV, Machado FC, Ferreira MA. Social inequalities and the oral health in Brazilian capitals. Cienc Saude Colet. 2015 Aug;20(8):2539-48. https://doi.org/10.1590/1413-81232015208.12052014

38. Costa SM, Martins CC, Pinto MQ, Vasconcelos M, Abreu MH. Socioeconomic factors and caries in people between 19 and 60 years of age: an update of a systematic review and meta-analysis of observational studies. Int J Environ Res Public Health. 2018 Aug;15(8):1775. https://doi.org/10.3390/ijerph15081775

39. Schneider MC, Castillo-Salgado C, Bacallao J, Loyola E, Mujica OJ, Vidaurre M et al. Methods for measuring inequalities in health]. Rev Panan Salud Publica 2002 Dec;12(6):398-414. Spanish. https://doi.org/10.1590/s1020-49892002001200006

40. Kissler SM, Klevens RM, Barnett ML, Grad YH. Dissecting the mechanisms of a 5-year decline in antibiotic prescribing. MedRxiv. https://doi.org/10.1101/2020.01.02.20016329

41. Kondo N, Sembajwe G, Kawachi I, Dam RM, Subramanian SV, Yamagata Z. Income inequality, mortality, and self rated health: metaanalysis of multilevel studies. BMJ. 2009 Nov;339 nov10 2:b4471. https://doi.org/10.1136/bmj.b4471 